\title{
Teaching the Conflicts: (Re)Engaging Students with Feminism in a Postfeminist World
}

\author{
MEREDITH A. LOVE AND BRENDA M. HELMBRECHT
}

\begin{abstract}
What happened to the dreams of a girl president
She's dancing in the video next to 50 Cent

They travel in packs of two or three

With their itsy bitsy doggies and their teeny-weeny tees

Where, oh where, have the smart people gone?

Maybe if I act like that, that guy will call me back

Porno Paparazzi girl, I don't wanna be a stupid girl

Baby if I act like that, flipping my blond hair back

Push up my bra like that, I don't wanna be a stupid girl

-Pink, "Stupid Girls"
\end{abstract}

If representational visibility equals power, then almost-naked young white women should be running Western culture.

-Peggy Phelan, Unmarked

There is no question that the work of feminists has benefited the daily lives, health, and financial status of many American women. In fact, some women's lives have been so improved that today's younger generation of women may not even know that "we've come a long way, baby" and, perhaps even more importantly, that we still have a long way to go. Even pop culture icons themselves, such as the musician Pink, recognize the current state of gender politics, lamenting the fact that young women today are more concerned with what they need to do and buy to maintain their image than they are with the positions of power they could someday hold.

Pink, an artist we will discuss at some length in this essay, is searching for "Outcasts and girls with ambition," because despite the fact that there are "Disasters all around" and a "World despaired, their only concern [is]: Will they fuck up my hair?" Certainly, Pink is prone to hyperbole, but her questions resonate: do young women still dream of being world leaders, or have their ambitions been curtailed in lieu of the smaller achievements they can make with their buying power? Peggy Phelan makes a similar point above, noting that "almost-naked young white women" are given great visibility in our culture, especially in advertisements, television, and film; yet it would be preposterous to suggest that their visibility instantly translates into power. Phelan continues to suggest that when women or anyone else who is "othered" in Western culture (including women and men of color, gays, lesbians and transsexuals; basically anyone who is not a white, heterosexual male) are given visibility, this visibility is often accompa- 
nied by surveillance, voyeurism, and the desire to possess another $(6-7)$. Thus, for this project, questions about whether a group is in some way made visible or represented in popular culture may be more productively framed as follows: What is the difference between an assumed image of empowerment and a "real" image of empowerment? And as feminist educators, how do we help students to tell the difference? Furthermore, what do the discourses of current third-wave feminism and postfeminism teach women about representation, empowerment, and their place in the realm of social action?

To explore these questions, we discuss three products of mass media-the musician Pink, the Dove Campaign for Real Beauty, and the film The Devil Wears Prada. In an attempt to better understand the relationship between young women and men and their own ability to effect change, we turn to these images of "strong" and "empowered" women. The depiction of women in each of these texts creates an interval where the relationship between personal empowerment and visibility via consumerism can be interrogated. Moreover, what we regard as a consumerism/activism split actually epitomizes the tension that manifests when the discourses of postfeminism and third-wave feminism become conflated. We suggest that teaching to the ideological conflicts that manifest within this convergence can serve to (re)engage students with the tenets and arguments of feminism.

\section{Moving Past the Second/Third Divide}

In order to ground our inquiry, we turn to an example from the classroom. Recently, Brenda had a conversation with a young woman minoring in women's studies. This self-identified "third-wave feminist," who also works in the women's center and volunteers at a shelter for abused women, asked, "Who is Gloria Steinem?" This student's commitment to improving the lives of women is commendable, yet we found ourselves troubled by the fact that a student preparing to graduate with a women's studies minor has nearly finished her work without learning about Steinem or understanding her contribution and, perhaps, the contributions of other second-wave feminists to the overall feminist project. This student has lingered in the back of our minds as we researched and wrote this article. In many ways, we find ourselves directing our pedagogical strategies to reach students like her: younger students who want to re-engage with gender theory and feminism but may be unfamiliar with the analytical tools that can support them as they try to find their place within the feminist movement. Of course, the experience of this one student doesn't allow us to make generalizations about the curricula of women's and gender studies courses. However, we find ourselves wondering if younger feminists would feel less alone in their beliefs if they could position their ideas and their work within a broader historical narrative about gendered struggles and the women's movement-within a context that is greater than both themselves and the third-wave feminist movement today.

Of course, many feminist scholars have recounted the tension and strain felt by the proponents of third-wave feminism and the second wavers that came before them. Yet in the Winter 2004 issue of Ms., Lisa Jervis, one of the co-founders and a former editor of Bitch magazine, claims that the term "third-wave feminism" 
is no longer useful, in part because of how much has been made of this divide between the questionably demarcated waves. Jervis's assessment of the socalled generational gap between feminisms has a deep history. She writes,

The rap goes something like this: Older women drained their movement of sexuality; younger women are uncritically sexualized. Older women won't recognize the importance of pop culture; younger women are obsessed with media representation. Older women have too narrow a definition of what makes a feminist issue; younger women are scattered and don't know what's important.

In a 1997 article in Hypatia, Catherine Orr notes that some third-wave texts reveal a distinctive desire to break away from second-wave feminism to create something entirely new (32-33); however, Orr also laments the breach between the two waves, writing that "Second wave 'moms' can and should be represented as something more than just oppressive to their third-wave "daughters"' (42). As an alternative, Orr proposes a supportive relationship: "What we must realize is that the inevitable reworking of the successes and failures of second wave feminism is underway, and the best place for second wave academics to be is where the action is. After all, if the second wave is history, then perhaps we should get to work on demonstrating to the next generation that it is a usable past" (42).

Lisa Maria Hogeland makes similar claims in her 2001 article, "Against Generational Thinking, or, Some Things that 'Third-Wave' Feminism Isn't.” Hogeland sorts out the various political positions taken by feminists in different movements to show that there is "nothing specifically generational about any of these feminisms" (108). She contends that there are too many generalizations made about second wave and third-wave feminism: "Attributing our differences to generation rather than to politics sets us firmly into psychologized thinking, and into versions of mother/daughter relations-somehow, we are never sisters who might have things to teach each other across our differences and despite our rivalries" (118).

However, as Jervis and Hogeland argue, it could be said that too much has been made of the differences between second and third-wave feminism, or that it has been discussed too much, at the expense of other, more important conversations. Jervis reminds us that "It's just so much easier to hit on the playful cultural elements of the third wave and contrast them with the brass-tacks agenda-and impressive gains-of the second wave: It's become the master narrative of feminism's progression (or regression, as some see it)."

Rather than dwell on the misunderstandings and animosities between second and third wave, we propose moving the discussion to one that understands the goals and objectives of men and women who self-identify as third-wave feminists. We contend that such an understanding hinges both on our ability to account for the effects of postfeminist thinking - which generally argues that the feminist movement is an historical entity, at best-and on the ability of the third wave to function as a coherent front.

\section{Voices of the Third Wave}

Third-wave feminism, like other feminisms, is not held to one, stable defini- 
tion. And just as second-wave feminism consisted of liberal, material, cultural, and other versions of feminism, the third wave also has several different voices and ideologies within it. There is no right way to be a feminist. However, after much reflection, we do hold to a definition of feminism that assumes a consciousness of social conditions and a commitment to the undoing of patriarchal systems. Although there never has and never will be a monolithic definition of the term "feminism," we subscribe to Judith Butler's simple definition: “Feminism is about the social transformation of gender relations" (204). In other words, feminism should be more than just an identity label. It must do. It must signify action.

Within this same vein, Rory Dicker and Alison Piepmeier, editors of the collection Catching a Wave: Reclaiming Feminism for the 21st Century, believe that

We need a feminism that is dedicated to a radical, transformative political vision, a feminism that does not shy away from hard work but recognizes that changing the world is a difficult and necessary task, a feminism that utilizes the new technologies of the Internet, the playful world of fashion, and the more clearcut activism of protest marches, a feminism that can engage with issues as diverse as women's sweatshop labor in global factories and violence against women expressed in popular music. (5)

The actual organization of the pieces within the collection "mirrors the process of consciousness-raising itself" (5) and includes diverse voices. Overall, the collection reflects the belief of the editors that "Ultimately, to be effective, feminism must embrace action, even when action calls us to make difficult choices" (19).
However, as we shall examine momentarily, third-wave voices, even those in this collection, do not always reflect this focus on transformation and action.

Bitch, a self-described third-wave feminist magazine that seeks to mesh critique with action, attempts to meet the objective spelled out by Dicker and Piepmeier. In particular, Bitch focuses on critiquing popular culture's representations of women, directing its attention to a broad array of media outlets, including film, television, publishing, and advertising. However, Bitch also regularly extends the arm of critique to the realm of social action with sections like "Where to Bitch." Within this regular feature, readers encounter information about current social issues as well as the organizations they can contact to better educate themselves and respond to injustices. In the Summer 2006 issue, for instance, "Where to Bitch" offers information about organizations that assist readers wanting to start campaigns against sweatshops; they also provide URLs where consumers can check on the toxicity of beauty products or the ethics of retailers (35). Readers of this zine will find feminist discourse that is smart, irreverent, and vibrant, but also focused on moving a feminist agenda forward.

However, Bitch may be an exciting exception to the rule. In their study of six third-wave feminist texts, Stacey Sowards and Valerie Renegar find that third-wave feminists "share their stories, listen to others' stories, consume popular culture in ways they find empowering, and create new vocabularies to enhance their own lives, but these activities do not necessarily lead to social activism in its traditional forms" (548). They may "embrace various forms of activism," but "they do not want to force individuals to take an activ- 
ist stance or assume that certain forms of activism are appropriate for all people" (548). It is this strand of the third wave that seems, at times, to be focused, even preoccupied, with personal freedom and desire, perhaps to the exclusion of social activism altogether.

In their introduction to Catching a Wave: Reclaiming Feminism for the 21st Century, Dicker and Piepmeier also identify a contradiction we have perceived in other third-wave texts. They write, "many in the third wave-in their attempt to complicate and broaden feminism, in their attempt to bring postmodern and poststructuralist theoretical concepts to bear on feminist theory and praxis-run the risk of abandoning feminist politics" (18), perhaps, we contend, in lieu of personal fulfillment. Although the editors acknowledge the dangers of moving too much towards the private end of the spectrum when constructing new feminist paradigms, the afterword at the end of Catching a Wave gives voice to a troubling thread in thirdwave feminism. This final section of the collection is structured as a conversation between third-wave author Jennifer Baumgardner and second-wave political columnist Katha Pollitt.

We believe that this conversation is more important in terms of what it tells us about third-wave feminism and postfeminism than in terms of what it does (or does not) add to the second/third-wave divide. Early in the conversation Baumgardner explains, "As you know, I am invested in claiming that there is a thirdwave and that younger women are taking feminism forward, toward greater freedom if not always toward stronger laws or more organized protests" and it is the "right and responsibility" of Baumgardner and her generation "to create a feminism that was relevant to my life and my values" (309). Baumgardner then acknowledges the advancements made possible by earlier feminisms that took on the important project of naming injustices regarding pay, equal opportunity, and sexual freedom; now, claims Baumgardner, the third wave must rebuild feminism for what's coming next. As other third-wave feminists have claimed, Baumgardner argues that younger feminists do not want to be tied to a fixed feminist identity that requires members to be "anti-capitalist, superserious, and hostile to bikini waxes and Madonna" (310).

Pollitt responds by applauding the next generation's interest in forming their own groups, yet she emphasizes that "society places rather serious limits on the ability of most women to live differently, even if they think differently. Those limits are subtler now-everything looks like a free choice" (313). Baumgardner then continues to argue that,

I guess I'm sensing that the personal frontier is where my generation is doing most of its work [... . ] and that is important work. Just as important as the lawchanging/tenure/first-woman-president stuff, because how we conduct our personal lives (what speaks to us, what we value) represents us directly-this is why the personal is political. [. . .] Feminism is about getting in touch with your true desires.[... ] ] believe in a feminism that strengthens my connections to my own desires. (316-17)

Pollitt seems perturbed by the focus on a feminism that is too focused on self-fulfillment: "I am all for following one's star and embracing one's 'true desires'-but who arranges the constellations in one's personal firmament? Where do those 'true 
desires' come from and in what social context does one pursue them?" (317). Pointing to the importance of examining the power of social forces on our "choices," Pollitt notes the countless ways that women are still disadvantaged financially, noting that sometimes a choice that looks like a "free" one can have dire consequences down the road. Pollitt concludes that "A feminism that doesn't raise these issues isn't worth much" (317) and that "feminists have to raise those uncomfortable, unsettling, infuriating questions about intimate relations and personal choices: it's not enough to say, 'Whatever floats your boat"' (318). Contradictions, as Pollitt suggests, must be uncovered, dealt with, and sometimes left as contradictions. But the personal cannot remain personal if social change is a goal. "YYou go, girl!' is a good slogan," writes Pollitt, "But it's not the only thing women need to hear. They also need to hear, from time to time, that old, infuriating, favorite saying of the hairy-legged ancients: the personal is political" (319).

Like Pollitt, we are struck by the use of the word "desire" here and struggle to account for such a feminist objective when introducing students to third-wave discussions. After all, it seems that such a focus on personal fulfillment can be at odds with the goals of a feminist pedagogy. Joy Ritchie points out that "Feminist classrooms are not simply revisionary because they break with canonical content; they are also revisionary because they demand critical rather than solipsistic modes of thought and because they assert an ethical rather than a nihilistic stance" (304). In our view, the goal of feminist pedagogy is to move students away from egocentrism and self-indulgent penchant for personal desire, a stance encouraged by media and consumerist culture, and into an activist stance that works to effect change.

We have this worry, in part, because of the virulent discourse of postfeminism, which tells young women to focus on the self and to consume in order to be empowered. These very messages-buttressed by media images of women made stronger by their purchasing power-allow for postfeminist ruminations that question the legitimacy and need for the entire feminist movement within the very social and cultural spaces that have been indisputably altered by feminist voices.

\section{Post What?}

In a recent gender studies course, Meredith presented her students with the statistic that 57 percent of college students today are women ("College"). Most of the women in the class smiled. One nontraditional student noted what a huge change this is from when she got her first college degree several decades ago, while a young man in the class confessed that he always thought about school as being a place with more women than men. However, faces in the room sobered a bit when they learned that fewer women hold powerful, decision-making positions in higher education than men and that women tend to earn more bachelor's and master's degrees than men, but hold fewer PhDs (Tyler). And they were shocked to learn that women who work full-time still earn only 77 percent annually as much as fulltime male workers (“Gender” 1).

We have found that, at times, statistics can be an effective persuasive strategy when discussing the need for continued attention to gender and women's issues in the U.S. As many feminist instructors (ourselves included) have learned, some stu- 
dents, particularly "traditional," younger university students, believe that there is no reason to fight for a feminist agenda anymore-a sentiment students freely express in our women's studies courses. We sometimes attribute this resistance to students never knowingly experiencing discrimination. Moreover, other students may be surprised by the data on success after college in part because of media messages that come wrapped up in postfeminist discourse, a term Angela McRobbie defines as

an active process by which feminist gains of the 1970 s and 1980 s come to be undermined. It proposes that through an array of machinations, elements of contemporary popular culture are perniciously effective in regard to this undoing of feminism, while simultaneously appearing to be engaging in a well-informed and even well-intended response to feminism. (255)

In her essay, "Negotiating Spaces For/ Through Third-Wave Feminism," Amber E. Kinser helps build on McRobbie's definition of postfeminism by conceding that

[p]ostfeminism very well may be a voice that is currently rising above the din for many young women. It is seductive. It co-opts the motivating discourse of feminism but accepts a sense of empowerment as a substitute for the work toward and evidence of authentic empowerment. (emphasis original; 134)

In response to the social and private advances second-wave feminists made (and continue to make), postfeminist texts subtly communicate the idea that feminism is "decisively aged and made to seem redundant” (McRobbie 255).

For instance, when looking through the lens of postfeminist discourse, media outlets might praise the statistic that 57 percent of college students are women but then ignore the darker truth behind the numbers about the positions women hold and their second-rate status in earnings. Although young women today leave college with education and opportunities, the flip side of that 57 percent remains obstructed from their view, for we seldom "see" popular images of successful women hitting a glass ceiling, contending with sexual harassment, or knowingly working next to a male coworker earning a higher salary.

We see a conflict here. We want women to understand that they do have power and agency and that they are strong and capable. Yet we also want students to see a difference between feeling empowered because the media says they are, and actually being empowered-through knowing women's history, from political engagement, by working collectively on cultural and social issues important to women. Such evidence of empowerment is often located in consumerism, where Yvonne Tasker and Diane Negra observe, "freedom is construed as the freedom to shop (and to cook), albeit [. . . ] with the option of an ironic mode" (107). Ann Braithwaite puts it this way: "The emphasis of this newer 'more fun' and 'groovier' postfeminism now allows women to (re)emphasize or return to lifestyle choices and personal consumer pleasures, rather than those older agendas for more direct kinds of social activism" (24). While we are comfortable pointing out the fallacies of postfeminist thinking for our students, we become conflicted when we observe some of the same focus on self-empowerment and consumerism in texts identified as being part of third-wave feminism. In 
many ways, we worry that postfeminism and its generally dismissive attitude toward feminist achievement and ideologies may slowly overtake the third-wave feminist movement.

Our campuses are certainly friendly to conversations about women's experiences, yet we still find ourselves contending with resistance in our classrooms that we trace back to the postfeminist influence of popular culture texts, which "are perniciously effective in regard to this undoing of feminism" (McRobbie 255). Chris Holmlund notes that despite its "longish" history, "the adjective 'postfeminist' has been applied to texts-from books and songs to TV programs and films to paintings, cartoons, and photographs-only since the 1980s," adding that Madonna is frequently cited as a "postfeminist queen" (117). We believe that popular texts, like film, music, and advertising, need to be brought into a classroom where they can be scrutinized, questioned, and studied through a gendered lens. Harriet Malinowitz, in an article exploring feminist writing theory, reminds us that "The goal of feminist education has never been to prepare students to participate in the world as it exists; the goal, rather, has been to help them develop the skills to deconstruct and transform that world" (310). Bringing to the classroom some of the most current and most popular images that our students see every day and studying them through lenses that highlight the postfeminist agenda give students a perspective that they can use to identify other such subtle messages and see the transformations that are still necessary.

As educators committed to helping students (re)engage with feminism, we must engage students in dialogue to help them bridge the gap between postfemi- nism and third-wave feminism. We would like to give students tools that they can use to move beyond the consumerist, self-focused nature of postfeminism and reconnect them with the socially motivated work of feminists, regardless of their wave. The overarching goal here is to help young women locate their own agency in a capitalist, androcentric media culture that is not invested in actually giving them any agency at all. Thus, when we consider the tenets of third-wave feminism, as we do in this article, we must keep in mind that it

is in the midst of [postfeminism's] bellowing voice that third-wave feminism begins to speak. [... ] Third-wave voices are clearly a response to the strength of postfeminism and its effective depoliticizing of feminist discourse, and therefore by definition are going to have a different articulation of what it means to be feminist and a different narrative of feminist living than second wavers. (Kinser 133, 135)

\section{Facing the Conflicts in the Classroom}

As women who grew up in the 1980s, we are, by the generational definitions associated with the "waves," third-wavers. Yet we believe that feminist educators who have been educated in the discourses of second-wave, third-wave, and postfeminist discourses are best equipped with experiences and theories that can help students understand the transformative power of feminism. In her essay, "Confronting the 'Essential' Problem: Reconnecting Feminist Theory and Pedagogy," Ritchie advocates taking a "both/and" position in a classroom when teaching within a feminist paradigm, because such a position allows her to "interpret more 
clearly the contradictory and conflictfilled experience of the students as they [attempt] to understand their position of women in our culture" (287).

Contradiction. Conflict. This is the stuff of feminist pedagogy. Any person who attempts to live and/or teach according to feminist theories and principles has experienced it. Ignoring contradiction and conflict in our classrooms would mean overlooking important teaching moments. This notion of both acknowledging and even seeking out the areas in a culture where conflicts abound can be attributed, in part, to Mary Louise Pratt, who argued for the arts of the "contact zone," or "social spaces where cultures meet, clash, and grapple with each other" (607). The metaphor of the contact zone serves to remind us that even within communities like universities and classrooms, we cannot "assume that principles of cooperation and shared understanding are normally in effect" and that "the situation is governed by a single set of rules or norms shared by all participants" (615). Rather, we need to encourage and nurture the voices of discord and critical inquiry. We certainly feel these tensions as we attempt to honor our identities as feminist educators in the midst of this ideological gap between feminisms. In Women Teaching for Change, Kathleen Weiler, drawing on the work of Paulo Freire and other critical pedagogues, reminds us of the importance of respecting the dignity of our students. In practice, this means making space for their voices in the classroom, even when we don't agree with them. Weiler writes, "The empowerment of students means encouraging them to explore and analyze the forces acting upon their lives" (152). Yet, this pedagogical choice itself becomes tricky because the ideas some students use their voices to express could be sexist, homophobic, or racist. So, in many respects, it also seems that an instructor's obligation is to teach students to use their voices in a way that does not further discriminatory agendas.

We work at universities where women's studies and gender studies programs are new to the curriculum. Even in courses like “Introduction to Women's Studies," students are hesitant to claim the term "feminist" and come with little understanding about the role that feminists have played in academic, social, historical, or legal realms. Many students enroll in the course to fulfill a "cultural pluralism" requirement; others are there because the class fit their schedule; some need to fill an upper-level writing requirement; others truly have an interest in conversations about gender politics. Because so few of our students can articulate their relationship to feminism in terms that are wholly positive, our task, then, becomes one of imagination. To best serve our students, we need to step into what might possibly be postfeminist thinking and realize that before asking them to take feminism "into account" we must (like them) regard it as "having already passed away" (McRobbie 255). In other words, many of our students approach feminism as an historical artifact, and our job becomes not just re-engagement, but also critical recovery and reclamation. While some students leave our courses happily applying "feminist" to their list of identities, others never become comfortable with it, seemingly unable to subtract the stereotypical "angry, man-hating, flannelwearing" associations attached to it. For instance, in an assignment that asks students to profile a woman in their lives who hails from a different generation, students often report that their own mothers, aunts, 
and grandmothers despise feminism and still struggle with the angry feminist icon who seems to haunt their understanding of the women's movement. It's no wonder that our students carry this same baggage with them.

At other universities with a different student population or curriculum, instructors might encounter students whose feminist identities are already solidified, who come to the classroom with a social agenda or an ideology. The pedagogical suggestions and discussions that we offer here work just as well with that population, for these moments in popular culture appeal to our desire to be empowered and to see ourselves as always already completely free from the hold of patriarchy or other oppression.

We want our students to use their voices, their writing, their skills of critical analysis to resist these discriminatory agendas, if they choose. Our experience has shown us that one of the most effective ways to help students (re)engage with feminist politics in our classroom is to ask them to look again at the mediatized culture surrounding them. Images create "teachable" moments that highlight some of the conflicting messages our students receive about gender. In How Images

Think, Ron Burnett uses

the term image to refer to a complex set of interactions that constitute everyday life within image-worlds. The ubiquitous presence of images far exceeds the conventional notions that images are just objects for consumption, play, or information. Images are points of mediation that allow access to a variety of experiences. (xix)

In addition, Sowards and Renegar have found that "many young women are empowered by female role models and become aware of their own oppression and the possibilities for emancipation through the consumption of popular culture" (544). Thus, we find popular culture an important pedagogical tool for (re)engagement with feminism.

Our task as educators, then, is to understand these interactions, these points of mediation, so that we can both relate to the worldview of our students and ask them to engage with images that complicate the ubiquity of the "self-empowerment via consumerism" message fed to them. We need to grapple with the gendered experiences students access by watching commercials, films, video games-any text that provides them with a framework to interpret their place in culture as a gendered being. Students approach images with varying levels of savvy and sophistication, such that some may claim to be unaffected by everything they see-as though saturation alone makes them immune to media's effects.

While reception studies have consistently pointed out the difficulty of ever truly understanding what happens when people cast their gaze upon a certain image, there is little debate surrounding the idea that images do matter, and that they do affect how people interact with and understand their place in the world. ${ }^{1}$ When people cast their eyes upon images, "[e]vents are no longer viewed through the simple relations of viewer and image; rather, viewers deal with increasingly complex discourses as they struggle to make sense of images that literally seep into every aspect of their lives" (Burnett 6). Thus, it makes sense to spend time with these contradictions and build them into our pedagogical and curricular choices. The three media texts we suggest here- 
the work of Pink, the Dove Campaign for Real Beauty, and the film The Devil Wears Prada-present images and messages that students consume, and are also suitable for illuminating the conflicts among both third-wave and postfeminist discourses and the dissolving line between consumerism and activism.

\section{PINK THINK}

In many ways, Pink simultaneously embodies and questions a consumerist impulse, and, in doing so, seems to be a perfect example of a cultural text that is situated squarely between the dual performances encouraged by postfeminism and third-wave feminism. In her song, "Stupid Girl," Pink defines "stupid girls" as young women who seek to live up to the beauty standards and consumer habits set by Hollywood stars (in her video she imitates Lindsey Lohan, Paris Hilton, and Jessica Simpson). In an interview with Oprah, Pink explained that she wrote the song to spark discussion about "mindless consumerism," about women not "questioning anything or contributing anything to the world." Oprah quickly pointed out that Pink has been called hypocritical because she has "bared just as much skin in [her] own videos." Pink replied: "My point is not that sexy is a bad thing; my point is that sexy and smart are not oil and water. You don't have to dumb yourself down to be cute. ... I think it's an act-it makes [a woman] less challenging as a female." In effect, Pink herself has been the very kind of icon she no longer wants "girls" to emulate.

Our point is that women are presented with "Pink" images that are both exploitative and commercial (and maybe even damaging)-yet this same image tells fans not to be so concerned with images. The hyper-sexual performance exemplified by Pink and others who argue for the power of personal choice can also be seen as a form of resistance to the second wave of feminism (which some say pits feminism and femininity against one another). Anthea Taylor writes that "in girlpower terms, embracing femininity becomes an act of defiance against both feminism (which rejects it) and patriarchy (which trivialises it)" (188). What concerns us is that Pink's audience may not recognize the implicit contradiction, but will live out this postfeminist hyper-femininity without pausing to consider the political message behind it.

As feminist educators who both consume and teach popular culture, we find ourselves troubled by students who largely define feminism and their relationship to it through public images like Pink, rather than through activist voices found in politics, books, or zines. Teaching Pink's song in tandem with self-proclaimed feminist activists like Ani DiFranco (who founded her own production company, Righteous Babe Records) allowed Brenda to further examine with her students the relationships among feminism, activism, and consumerism. As she had predicted, few students were familiar with DiFranco while most had downloaded "Stupid Girl" onto their iPod-a fact that prompted discussions of the kinds of feminists and feminist statements that "sell."

Research has shown that young women's impressions of what feminism means are often learned from the media. For instance, in an interview project conducted with early-adolescent girls, Melanie Lowe discovered that young women have learned a lot about their sexuality from the music and public performances of music icons like Spears: "While the girls 
feel offended and angry when women's bodies are objectified in media, many of them are surprisingly empowered by the idea that women themselves might choose to use their own bodies for personal or-in the case of Britney Spears-professional gain" (135). Interestingly enough, Lowe also found that these young women were active readers of the images they saw of Spears, yet she concluded that "Their individual readings of various media texts frequently frustrate them, particularly when their feminist consciousness engages the increasingly decentered self of pop culture and postfeminism" (139). As educators, we want to ask students if they feel empowered, embarrassed, voyeuristic, or even indifferent and/or confused as they gaze upon Britney Spears's naked, pregnant body on the cover of Harper's Bazaar Magazine while standing in line at the grocery store. Or if they are angry when they hear Pink criticize other women in her attempt to be both sexy and smart. The messages are, no doubt, mixed, and the classroom may be a place for students to sort them out together.

\section{CAMPAIGN FOR “REAL” BEAUTY}

Another purveyor of contradictory messages is Dove. In a recent advertising campaign, Dove claims women's social and sexual empowerment as a goal. From the get-go, Dove's "global" "Campaign for Real Beauty" positioned itself as being wholly altruistic, intending to "serve as a starting point for societal change" ("Campaign"). The campaign "aims to change the status quo and offer in its place a broader, healthier, more democratic view of beauty. A view of beauty that all women can own and enjoy every day" ("Why"). Dove chooses "real" women as models, and claims not to have airbrushed or oth- erwise altered the images that appeared on billboards, in commercials, and in magazines.

In addition, one of Dove's campaign/ advertising goals is to "create a forum for women to participate in a dialogue and debate the standards of beauty in society" ("Why"); such "conversation" transpires on Dove's website where viewers encounter images of women of all ages, sizes, and skin tones. The site asks viewers to vote on whether the featured womanwho changes each time you reload the site-is "flawed" or "flawless," "wrinkled" or "wonderful," by clicking on the appropriate box. Of the $1,870,950$ people who voted to determine if a woman was "oversized" or "outstanding" in August 2006, 44 percent opted for oversized. Is Dove truly challenging beauty standards, or subtly reifying popular notions of beauty? The products Dove sells-including firming lotion, moisturizers, and self-tanning lotion, each of which presumably helps the wrinkled, flawed, and oversizedappear as mere afterthoughts to the larger cause of helping women focus on their own needs.

In creating these spaces where consumerism and activism mingle awkwardly, Pink and Dove implicitly argue that women's empowerment and advancement lie within an individual's buying power, not within a larger cultural cause or movement. In other words, gender politics have become conflated with consumerism. When she recently taught a course in Women's Rhetoric, Brenda brought the Dove campaign to her students. As she expected, the class (comprised of women) was familiar with the campaign, and could describe the images associated with it with little prompting. They praised the images as being "unique" and a "welcome 
change" from the images they regularly encountered in Vogue and Cosmo. After spending a few hours on the Dove website for homework, students posted their responses to an online discussion forum. For the first time, they began to witness how a capitalist enterprise had appropriated women's "rhetoric of empowerment" to sell a product. Images that once made some of the women in the course feel better about their bodies now made them feel more like mere customers. In short, they felt duped.

Meredith's students in a Gender and Rhetoric course had a similar reaction when they came across the portion of the website that asked them to vote on whether a featured woman was beautiful or oversized. After reading the introductory materials on the site that discussed the importance of teaching young girls about healthy self-image and reading about Dove's commitment to make "real women" more visible, they felt betrayed when they were asked to then participate in "othering" women with "atypical" body types. Additionally, these students were also shocked to see that the women on the "Real Women Have Curves" page of the site were not really that curvy at all, at least not curvy enough to be a size 12 or up. Students experienced a sort of intellectual and emotional discomfort with the new paradigm this conversation established. The self and the product had become all mixed up-a message of empowerment was, in effect, being used against them. Their wallets were lighter, yet they felt no more empowered than before they purchased the product.

Although we are certainly not the first feminist scholars to point out the ways in which consumerism and feminist activism have become conflated, we are still struck by the novelty of this concept when it is presented to the women in our classrooms. Yet, once students have considered the relationship between activism and consumerism, some do so eagerly. For instance, one of Brenda's students, Frances, ${ }^{2}$ decided to explore this connection in the third-wave feminist zine she is designing for her senior project. In one of her compositions, titled “The Dynamics and Complexities of Consumerism as Activism," Frances critiques the new [PRODUCT] RED campaign that seeks to fight AIDS in Africa. To support the campaign, people can purchase a RED product at a store like the Gap or Apple and, as Frances observes, "walk down the street" thinking they are an activist in the fight against AIDS in Africa. Frances continues,

Many young women of today consider their consumption of certain products that support "good" causes as one and the same with developing a critical political consciousness. This lack of truly grasping the issue, whether it be AIDS, sustainability, or breast cancer, limits both the social or environmental issue itself as well as the consumer. If the consumer's foundation for understanding an issue is based upon and associated with the product they purchased, there is a disconnect between buying the product and supporting the cause. ... Society, and third wave feminists in particular, needs to understand the complexities of the issues within society in order to truly change their community. The development of a critical social and political awareness is absolutely necessary to make change.

Yet even Frances, who clearly wants to live out feminist principles, struggles to untangle her power as a consumer from her power as a feminist. Though students 
are not necessarily passive consumers of all images and products, we urge them to think about the images they consume in a new, critical framework that questions the relationships among consumerism, gender, and feminism. This pedagogical framework mimics one Weiler discusses. In describing a group of feminist teachers she has interviewed, Weiler writes, "they are describing the classroom as a place where consciousness is interrogated, where meanings are questioned, and means of analysis and criticism of the social world as well as of a text or assignment are encouraged" (114). Foregrounding the contradictions and struggles both within ourselves and within movements enables necessary conversations that may help students better understand their positions regarding feminism.

\section{THE FEMINIST DEVIL}

Undoubtedly, popular culture contributes to a capitalist version of a postfeminist discourse of empowerment. Thus, teaching popular films with which students are already familiar can provide another tactic instructors can use to engage students with gendered images in a classroom. For example, in many filmic depictions of independent and successful women, the lead female characters are often impoverished in the arena of their homes, families, and friendships.

In 2006's hit film The Devil Wears Prada, Andy Sachs (Anne Hathaway), a recent ivy league graduate with no fashion sense or any real desire to work in fashion, is hired at Runway magazine because her frumpiness and glasses seem to signify a kind of librarianesque reliability. As a young woman with career ambitions, Andy is the character audiences are meant to identify with-in short, a third-wave role model. On the other hand, the icy, aging editor Miranda Priestly (Meryl Streep) is the third wave's worst nightmare. She has power, but lacks happiness. In a discussion of backlash and postfeminism, Braithwaite writes, "Women today, the theory goes, are more miserable precisely because of those changes that 1970 s feminism brought about, and everything that feminism demanded for and in the name of women-for example, being able to 'have it all'-only succeeded in making them more miserable than ever" (22). Miranda evokes second-wave feminism, whose advancements served to make her "more miserable" than anyone else in the film.

The Devil Wears Prada is a prime candidate for exploring with students competing media depictions of strong, successful women. Students may be familiar with both Andy and Miranda, and, as a class, can identify other imagistic representations of the "bitch boss." These sorts of discussions can serve as an introduction to this film or to others that seem to perpetuate the unhealthy "us/them" dichotomy that often stands in the way of women organizing across generational lines. By the end of the film, Andy chooses to leave her work, haunted perhaps by the fear that she will become Miranda. She instead chooses a low-paying job with a local newspaper, reconnects with her boyfriend, and leaves the film with a spring in her step. The Devil Wears Prada presents a false choice-women must choose between career success and personal success-and, in turn, tells the story that women can be financially successful only by paying the hefty price of personal unhappiness. Furthermore, the underside of these representations takes us back to the fact that women earn 23 percent 
less than men. The Devil Wears Prada and other films like it send the message that earning less than men is not only okay but also necessary. For "running with the big boys" takes an emotional toll that men seemed better equipped to handle than women. The message: "You might earn less, but you'll be happier."

The Devil Wears Prada can also provoke an investigation into the lives of women in the workplace, about which there are questions that the film does not pose, including: What were Miranda's options in terms of maternity leave and day care when she had her children? What would happen to Andy's career if she were to start a family by adopting a child? What are the options for women and men who are harassed at work? Thus, this film is an excellent starting point for research projects, presentations, and discussions about legislation-both past and presentthat affects women's lives. In presenting us with false dichotomies and simplistic generational and gendered depictions, The Devil Wears Prada actually leaves more room for negotiation and interpretation than more complicated stories of women's working lives as depicted in films like North Country and Erin Brockovich. This film creates an environment where students can critique depictions that they already identify with, thereby allowing us, as a class, to critique our own places as women in higher education.

Additionally, the film encourages the "generational divide" between second and third wavers. Miranda is presented as embodying the "qualities" Andy both admires and does not want to possess. However, we suspect that Andy's professional career trajectory will be much smoother than Miranda's, for it is women like Miranda who helped to pave the way for the next generation. Writing projects that encourage students to reflect on their own lives and career aspirations and then search out women who might have made these paths possible, would give students the chance to connect their desires with history and the larger feminist project.

\section{Coming to Terms with the Conflicts}

In her foreword to The Fire This Time, Rebecca Walker admits that she did not foresee how easily the acts of consumerism and activism would be mistaken for one another: she now feels "shortsighted in that we did not anticipate that young women and men would think that buying books or magazines, or supporting films and fashion that reflected diverse beauty and beliefs, could replace many important struggles to be waged against an unjust system" (xix). Many of our students frequently make this same error. They may look to make-up counters, fashion magazines, name brands, and images that tell them that the consumption of a particular product or idea will empower them. Yet, the irony here is that the act of critiquing these products and their effect on female consumers within a capitalist market will bring them closer to empowerment than anything they can buy.

Unlike activism, which tends to encourage coalition building and collaboration, consumerism is a choice driven by marketing and individualism. Although Walker does not draw this connection, we think it's fair to say that when consumerism and activism become mistaken for one another, we can reasonably conclude that postfeminism has overtaken third-wave women's conception of social change as evidenced by the dialogue between Baum- 
gardner and Pollitt. And if we lose our drive for social change, then feminism is truly over. Thus, as feminist pedagogues, we have an agenda. Every text or speech or act of consciousness raising need not be focused on activism or social change, but we hope that a pedagogy that seeks not only to teach students about feminism but also encourages them to engage and thus to act might thwart the pull of postfeminism and enable third-wave feminism to make a mark on women's lives today and in the future. (Re)engagement with social issues could lead to social activism.

We offer the previous three image-based texts as fodder for classrooms that focus on gender representations-the kind of representations students interact with as consumers and viewers on a near-daily basis. Since interaction demands analysis, it also presents a teaching moment. We present these texts because they take gender as a focal point, a means of disseminating meaning with gender at the center. When we argue for feminist pedagogy that seeks to (re)engage students with feminism-its history, its leaders and activists, its arguments - we want to do so because we fear that if post-wave feminism stifles the great potential that third-wave feminism offers, fewer and fewer students will want to see themselves as feminists. Furthermore, when we think of feminist pedagogy, we, as feminists, teachers, and researchers, need to remember that the experiences and knowledge of the second-wave feminists who trained and mentored us, the third-wave feminists we teach and befriend, and feminists who don't claim a wave, offer knowledge that must be accounted for in our classrooms.

In The Feminist Classroom, Frances A. Maher and Mary Kay Tetreault assert that to them, "the term 'pedagogy' was not about teaching techniques, divorced from content, but rather about the whole process of knowledge construction, in the classroom as elsewhere. Positional pedagogies attend to the complex social dynamics of difference and inequality as an integral part of this process" (10). The pedagogy we are arguing for is invested in understanding "knowledge construction," as knowledge about gender and feminism is, in many ways, constructed by the images we see. Certainly the three texts we discuss here could, and should, be enhanced in a classroom with more imagistic texts that focus on representations of gender, particularly texts that offer contradictory and confusing messages. Instructors can provide students with a framework for understanding gender representations in texts, and, in turn, students should be invited to bring into the classroom texts with which they are grappling. There they can work with their peers to generate gendered readings of these texts. Making a space where the media's version of the "norm" can be questioned is essential to a feminist pedagogy because "confronting what is contradictory and alienating in human experience allows women and men to resist definitions that society would impose" (Ritchie 320).

\section{NOTES}

1. See John Berger, Teresa de Lauretis, Susan Faludi, Trinh T. Minh-Ha, Susan Bordo, and Jay David Bolter, among many other scholars.

2. Frances has granted us permission to quote from her zine for our project.

\section{REFERENCES}

Berger, John. Ways of Seeing. London: British Broadcasting Corporation and Penguin Books, 1977. 
Bolter, Jay David, and Richard Grusin. Remediation: Understanding New Media. Cambridge, Mass.: MIT Press, 2000.

Bordo, Susan. Unbearable Weight: Feminism, Western Culture, and the Body. Berkeley: University of California Press, 1993.

Braithwaite, Ann. "Politics of/and Backlash." Journal of International Women's Studies 5.5 (June 2004): 18-33.

Burnett, Ron. How Images Think. Cambridge, Mass.: MIT Press, 2005.

Butler, Judith. "The Question of Social Transformation.” Undoing Gender. Ed. Judith Butler. New York: Routledge, 2004. 204-31.

“Campaign for Real Beauty Background." Dove: Campaign for Real Beauty. Unilever. 2 August 2006 <http://www.campaignforrealbeauty. com>.

“College Enrollment Gender Gap Widens for White and Hispanic Students, but Race and Income Disparities Still Most Significant New ACE Report Finds." Higher Education \& National Affairs Online News. 11 July 2006. American Council on Education. 27 July 2006 < http://www.acenet.edu/AM/Template. $\mathrm{cfm}$ ?Section $=$ HENA\&TEMPLATE $=/ \mathrm{CM} /$ ContentDisplay.cfm\&CONTENTID $=17251$.

de Lauretis, Teresa. Technologies of Gender: Essays on Theory, Film and Fiction. Bloomington: Indiana University Press, 1987.

The Devil Wears Prada. Dir. David Frankel. Twentieth Century-Fox, 2006.

Dicker, Rory, and Alison Piepmeier. Catching a Wave: Reclaiming Feminism for the 21st Century. Boston, Mass.: Northeastern University Press, 2003.

Faludi, Susan. Backlash: The Undeclared War Against American Women. New York: Crown Publishers, 1991.

“The Gender Wage Ratio: Women's and Men's Earnings.” Institute for Women's Policy Research. Updated August 2006. 25 June 2007 〈http://www.iwpr.org/pdf/ Updated2006_C350.pdf .

Hogeland, Lisa Maria. “Against Generational Thinking, or, Some Things That 'Third-Wave' Feminism Isn't." Women's Studies in Communication 24.1 (Spring 2001): 107-21.

Holmlund, Chris. "Postfeminism from A to G." Cinema Journal 44 (2005): 116-21.
Jervis, Lisa. “The End of Feminism's Third Wave: The Cofounder of Bitch Magazine Says Goodbye to the Generational Divide." Ms. Winter 2004. 28 January 2007 <http://www. msmagazine.com/winter2004/thirdwave. asp.

Kinser, Amber E. "Negotiating Space For/ Through Third-Wave Feminism." NWSA Journal 16.3 (2004): 124-54.

Labaton, Vivien, and Dawn Lundy Martin, eds. The Fire This Time: Young Activists and the New Feminism. New York: Anchor Books, 2004 .

Lowe, Melanie. "Colliding Feminisms: Britney Spears, 'Tweens," and the Politics of Reception." Popular Music and Society 26.2 (2003): 123-40.

Maher, Francis A., and Mary Kay Thompson Tetreault. The Feminist Classrooom. Lanham, Md.: Rowman and Littlefield Publishers, 2001.

Malinowitz, Harriet. "A Feminist Critique of Writing in the Disciplines." Feminism and Composition Studies: In Other Words. Ed. Susan Jarratt and Lynn Worsham. New York: MLA, 1998. 291-312.

McRobbie, Angela. "Post-Feminism and Popular Culture." Feminist Media Studies 4.3 (November 2004): 255-64.

Orr, Catherine. "Charting the Currents of the Third Wave." Hypatia 12.3 (Summer 1997): 29-45.

Phelan, Peggy. Unmarked: The Politics of Performance. New York: Routledge, 1993.

Pink. Interview with Oprah Winfrey. The Oprah Winfrey Show. NBC. 10 April 2006.

—_. "Stupid Girls." I'm Not Dead. La Face. 4 April 2006.

Pollitt, Katha, and Jennifer Baumgardner. "Afterword." Catching a Wave: Reclaiming Feminism for the 21st Century. Ed. Rory Dicker and Alison Piepmeier. Boston, Mass.: Northeastern University Press, 2003. 309-19.

Pratt, Mary Louise. "Arts of the Contact Zone." Profession 91. New York: MLA, 1991. 33-40. Rpt. in Ways of Reading: An Anthology for Writers. 6th Ed. Ed. David Bartholomae and Anthony Petrosky. Boston: Bedford/St. Martin's, 2002. 605-19. 
Ritchie, Joy. "Confronting the 'Essential' Problem: Reconnecting Feminist Theory and Pedagogy." The Kinneavy Papers. Eds. Lynn Worsham, Sidney Dobrin, Gary A. Olson. New York: SUNY Press, 2000. 279308.

Sowards, Stacey, and Valerie R. Renegar. "The Rhetorical Functions of ConsciousnessRaising in Third Wave Feminism." Communication Studies 55.4 (Winter 2004): 535-52.

Tasker, Yvonne, and Diane Negra. "In Focus: Postfeminism and Contemporary Media Studies." Cinema Journal 44.2 (2005): 107-10. Taylor, Anthea. "What's New About 'the New Femininity'? Feminism, Femininity and the Discourse of the New." Hecate 29.2 (2003): 182-98.

Trinh T. Minh-Ha. When the Moon Waxes Red:
Representation, Gender and Cultural Politics. New York: Routledge, 1991.

Tyler, Raven. “Gender Gap 101.” NewsHour Extra. 2 October 2002. 26 July 2006 <http:// www.pbs.org/newshour/extra/features/julydeco2/college.html.

Walker, Rebecca. "Foreword: We Are Using This Power to Resist." The Fire This Time. Eds.

Vivien Labaton and Dawn Lundy Martin. New York: Anchor Books, 2004. xi-xx.

Weiler, Kathleen. Women Teaching for Change: Gender, Class and Power. New York: Bergin and Garvey Publishers, 1988.

"Where to Bitch." Bitch. Summer 2006: 35. "Why the Campaign for Real Beauty?" Dove: Campaign for Real Beauty. Unilever. 2 August 2006 <http://www.campaignforrealbeauty. com>. 